\title{
Meijer and Vloedman's histochemical demonstration of mitochondrial coupling obeys Lambert-Beer's law in the myocardium
}

\author{
Eva L. Peters ${ }^{1,2}$ (D) David Comerford ${ }^{1} \cdot$ Frédéric M. Vaz $^{3} \cdot$ Willem J. van der Laarse $^{1}$
}

Accepted: 24 August 2018 / Published online: 29 August 2018

(c) The Author(s) 2018

\begin{abstract}
Uncoupling of mitochondrial proton pumping and adenosine triphosphate (ATP) production lowers mitochondrial efficiency. Current methods to determine mitochondrial efficiency require substantial amounts of tissue and permeabilization or isolation procedures. A simple histochemical method has been described by Meijer and Vloedman (Histochemistry 69:217-232, 1980, https://doi.org/10.1007/BF00489769), but this was not quantitative. We found linear correlations between (1) absorbance and sections thickness and (2) absorbance and incubation time. Because the method obeys Lambert-Beer's law, we can estimate ATP $/ \mathrm{O}_{2}$ ratios for healthy and overloaded right-sided rat myocardium. We related mitochondrial efficiency to the ratio between cardiolipin and its precursor phosphatidylglycerol. We found a non-linear relationship between mitochondrial efficiency and this ratio, indicating that lower mitochondrial efficiency as found in experimental pulmonary hypertension may be due to altered composition of the mitochondrial inner membrane. We conclude that the histochemical method of Meijer and Vloedman can be applied to quantify mitochondrial efficiency.
\end{abstract}

Keywords Pulmonary hypertension $\cdot \mathrm{F}_{1} \mathrm{~F}_{\mathrm{o}}$ ATPase $\cdot$ Oxidative phosphorylation $\cdot$ Histochemistry $\cdot$ Mitochondrial coupling $\cdot$ Heart failure

\section{Introduction}

Mitochondrial uncoupling of oxygen consumption and adenosine triphosphate (ATP) resynthesis may play a role in various pathologies. Increased $\mathrm{Mg}^{2+}$-stimulated ATPase activity and thus loosely coupled mitochondria, was shown to be a feature of some neuromuscular diseases (Meijer and Vloedman 1980). Also, in cardiomyopathy, mitochondrial dysfunction may play a critical role (Murphy et al. 2016). Decreased right-sided myocardial efficiency of pulmonary

Eva L. Peters

el.peters@vumc.nl

1 Department of Physiology, Amsterdam Cardiovascular Sciences, Amsterdam UMC, Vrije Universiteit Amsterdam, De Boelelaan 1117, Amsterdam, The Netherlands

2 Department of Pulmonary Medicine, Amsterdam Cardiovascular Sciences, Amsterdam UMC, Vrije Universiteit Amsterdam, De Boelelaan 1117, Amsterdam, The Netherlands

3 Department of Clinical Chemistry, Amsterdam Gastroenterology and Metabolism, Laboratory Genetic Metabolic Diseases, Amsterdam UMC, University of Amsterdam, Meibergdreef 9, Amsterdam, The Netherlands hypertensive patients and myocardial preparations of rats (Wong et al. 2010, 2011; Pham et al. 2018) may also be due to uncoupling and a concomitant decrease in the efficiency of mitochondria.

Mitochondrial efficiency measured in intact muscle preparations is $70-80 \%$ (corresponding to ATP/ $\mathrm{O}_{2}=5$ ), indicating that at most $20-30 \%$ of the available energy of substrate oxidation is spent on futile ion pumping and heat generation (Lou et al. 2000; Barclay and Widen 2010). The flux of protons crossing the inner membrane without generating ATP by $\mathrm{F}_{1} \mathrm{~F}_{\mathrm{o}} \mathrm{ATPase}$ dissipates part of the chemiosmotic proton potential generated by the electron transport chain. Proton permeability of the inner membrane is regulated by uncoupling proteins and hormones and depends on the fatty acid composition of cardiolipin (Hoch 1998). When the futile flux of protons across the mitochondrial inner membrane increases, e.g., due to radical damage to the inner membrane, ATP generation by $F_{1} F_{0}$ ATPase is disturbed.

Unfortunately, it is often impossible to determine the coupling state of mitochondria in intact preparations because this requires measurements of heat production and/or oxygen consumption and corrections for glycolytic ATP production. Current methods use permeabilized 
biopsies or isolated mitochondria to determine the coupling state biochemically. The latter methods require relatively large amounts of tissue (50 $\mathrm{mg}$ or more). It is also usually unknown how permeabilization or isolation procedures affect the coupling state (Picard et al. 2011). This is especially important because the isolation and permeabilization procedures often need to be optimized differently for test and control tissue.

We studied the possibility to determine the coupling state of mitochondria quantitatively in cryosections of rat myocardial tissue, using the histochemical method as described by Meijer and Vloedman (1980). The method is based on determination of MgATPase activity of $\mathrm{F}_{1} \mathrm{~F}_{\mathrm{o}}$ ATPase operating in the reverse mode, i.e., pumping protons out of the mitochondrial matrix using energy from ATP hydrolysis. We investigated whether this histochemical method obeys Lambert-Beer's law with respect to the relationship between absorbance and incubation time and the relationship between absorbance and section thickness. Furthermore, we applied the quantification to right ventricular myocardial tissue from control and pulmonary hypertensive rats, and related proton permeability to a marker of cardiolipin metabolism.

\section{Methods}

\section{Animals}

The study was approved by the Animal Experimental Committee of the Vrije Universiteit Amsterdam (Amsterdam, Netherlands). All procedures performed involving animals were in accordance with the guide of the Dutch Research Council for care and use of laboratory animals.

To investigate whether the method obeys Lambert-Beer's law, four male Wistar rats (body weight ranging from 262 to $341 \mathrm{~g}$ at time of experiment, Envigo, The Netherlands) were used. Rats were anesthetized with isoflurane, and hearts were excised and perfused with HEPES-buffered, oxygenated Tyrode [in mM: $\mathrm{NaCl} 140, \mathrm{KCl} 4.7, \mathrm{MgSO}_{4} \cdot 7 \mathrm{H}_{2} \mathrm{O} 1.2$, $\mathrm{NaH}_{2} \mathrm{PO}_{4} \cdot \mathrm{H}_{2} \mathrm{O}$ 2,2,3-butanedione monoxime (BDM) 20, $\mathrm{CaCl}_{2} 1$, HEPES 5, glucose $\left.10, \mathrm{pH}=7.4,10-15^{\circ} \mathrm{C}\right]$.

To investigate the effect of right ventricular overload on the coupling state of mitochondria in pulmonary hypertensive rats, another four healthy animals were compared with 11 monocrotaline (MCT) treated animals. Tissue was obtained 23 days after subcutaneous MCT injection $(60 \mathrm{mg} /$ $\mathrm{kg}$ ) as described elsewhere (Van Eif et al. 2014). In both cases, the apex and right ventricular free wall were isolated and frozen in liquid nitrogen. $\mathrm{F}_{1} \mathrm{~F}_{\mathrm{o}} \mathrm{ATPase}$ was determined within 1 week after collection of the tissue. Tissue was stored at $-80^{\circ} \mathrm{C}$ for further analyses.

\section{Determination of $F_{1} F_{0} A T P a s e$ activity}

Meijer and Vloedman's method for complex V activity is based on the determination of $\mathrm{F}_{1} \mathrm{~F}_{\mathrm{o}}$ ATPase activity in a Wachstein-Meisel medium (Meijer and Vloedman 1980). Maximum activity was obtained in the presence of 2,4-dinitrophenol (DNP, Fluka Chemie, Switzerland) which carries protons across the mitochondrial inner membrane. Background activity was measured after inhibition of $\mathrm{F}_{1} \mathrm{~F}_{\mathrm{o}}$ ATPase by oligomycin (Sigma, The Netherlands).

Sections were cut in a Leica CM 1950 cryostat (Nussloch, Germany). For determination of the absorbance as a function of incubation time, sections of $5 \mu \mathrm{m}$ thickness were incubated for $30 \mathrm{~s}, 5 \mathrm{~min}, 10 \mathrm{~min}$ or $15 \mathrm{~min}$. To determine the absorbance at different section thicknesses, sections of 2-8 $\mu \mathrm{m}$ thick were cut and incubated for $10 \mathrm{~min}$. The sections were fixed for $2 \mathrm{~min}$ on ice in Macrodex $\left(0.9 \% \mathrm{NaCl}, 1 \% \mathrm{CaCl}_{2}, 3.6 \%\right.$ formalin, $7.7 \mathrm{mM}$ dextran-70) and subsequently washed four times in $0.9 \%$ $\mathrm{NaCl}^{+} 1 \% \mathrm{CaCl}_{2}$. Sections were then incubated at $37^{\circ} \mathrm{C}$.

The different incubation media were prepared from stock solutions of $0.2 \mathrm{M}$ Tris maleate ( $\mathrm{pH} 7.2), 60 \mathrm{mM}$ $\mathrm{Pb}\left(\mathrm{NO}_{3}\right)_{2}$, and $50 \mathrm{mM} \mathrm{MgCl} 2$. ATP- and oligomycin solutions were freshly made. ATP disodium salt (Sigma, The Netherlands) was dissolved in water and kept on ice until use. Oligomycin was dissolved in ethanol $(1 \mathrm{mg} / 40 \mu \mathrm{l})$. Final concentrations were $80 \mathrm{mM}$ Tris maleate, $3.6 \mathrm{mM}$ $\mathrm{Pb}\left(\mathrm{NO}_{3}\right)_{2}, 5 \mathrm{mM} \mathrm{MgCl}{ }_{2}, 1 \mathrm{mM} \mathrm{Na}_{2} \mathrm{ATP}$, and $25 \mu \mathrm{M}$ oligomycin and/or $1 \mathrm{mM}$ DNP. The $\mathrm{pH}$ was adjusted to 7.2 using $1 \mathrm{~N} \mathrm{NaOH}$.

To test whether oligomycin inhibition was timedependent, we pre-incubated sections for $30 \mathrm{~min}$ at $37^{\circ} \mathrm{C}$ in medium with oligomycin, but without lead nitrate and subsequently incubated in the medium containing both oligomycin and lead nitrate. To determine non-specific binding of lead, sections were incubated without ATP.

After the incubation, sections were washed quickly in four changes of water and developed in $1 \% \mathrm{Na}_{2} \mathrm{~S}, \mathrm{pH} 7.5$ at room temperature for 1-2 min. Finally, sections were washed again and mounted in glycerin-gelatin.

\section{Microdensitometry}

Images of the sections were captured using NIH image and analyzed using ImageJ (version $1.51 \mathrm{u}$, http://rbs.info.nih. gov) as described previously (Lee-de Groot et al. 1998). None of the images have been manipulated. The absorbance of the final $\mathrm{PbS}$ precipitate in the sections was determined at $550 \mathrm{~nm}$ in individual myocytes. The absorbances of ten myocytes, cut perpendicularly to the longitudinal axis, were measured in the center of the cell (excluding 
nuclei). The extinction coefficient of the $\mathrm{PbS}$ precipitate at $450 \mathrm{~nm}$ is $3788 \mathrm{SD} 797 \mathrm{M}^{-1} \cdot \mathrm{cm}^{-1}$ (Van Noorden and Jonges 1992). At this wavelength, the absorbance is high at 10 min incubation time in 5- $\mu$ m-thick myocardial sections ( $>1$ in positive controls), therefore we prefer absorbance measurements at $550 \mathrm{~nm}$. The absorbance of $\mathrm{PbS}$ decreases continuously with increasing wavelength $>420 \mathrm{~nm}$ (Laborde et al. 1990). The ratio of absorbances at $550 \mathrm{~nm}$ over $450 \mathrm{~nm}$ measured in myocardial sections was constant up to $A_{450 \mathrm{~nm}}=0.6$ and equaled $0.54 \pm 0.02$ [mean $\pm \mathrm{SD}, n=4$; confirming results of Laborde et al. (1990)], indicating that the molar extinction coefficient of $\mathrm{PbS}$ at $550 \mathrm{~nm}$ equals $2046 \mathrm{M}^{-1} \cdot \mathrm{cm}^{-1}$. We assume that the extinction coefficient at $550 \mathrm{~nm}$ with respect to phosphate equals $3069 \mathrm{M}^{-1} \cdot \mathrm{cm}^{-1}$ since the solubility product of $\mathrm{Pb}_{3}\left(\mathrm{PO}_{4}\right)_{2}$ is reached before the solubility product of $\mathrm{PbHPO}_{4}$ is reached at $\mathrm{pH}$ 7.2. A similar value has been reported by Blanco and Sieck (1992).

\section{Coupling state of mitochondria: quantitative estimate of proton permeability and corresponding ATP $/ \mathbf{O}_{2}$}

It is assumed that $\mathrm{F}_{1} \mathrm{~F}_{\mathrm{o}}$ ATPase activity is negligible in the presence of $25 \mu \mathrm{M}$ oligomycin $\left(\mathrm{IC}_{50}=0.092 \mu \mathrm{M}\right.$, Nesci et al. 2014) and that proton permeability is maximal in the presence of $1 \mathrm{mM}$ 2,4-dinitrophenol (Heytler and Prichard 1962). The estimate of ATP/O $\mathrm{O}_{2}$ based on energy dissipation due to proton permeability of the inner membrane is calculated assuming the $\mathrm{F}_{1} \mathrm{~F}_{\mathrm{o}}$ ATPase activity is proportional to the proton flux across the inner membrane into the matrix:

$$
\begin{array}{r}
\text { ATP } / \mathrm{O}_{2}=6.3\left[1-\left(\mathrm{F}_{1} \mathrm{~F}_{\mathrm{o}} \text { ATPase activity } /\right.\right. \\
\left.\mathrm{F}_{1} \mathrm{~F}_{\mathrm{o}} \text { ATPase activity with DNP }\right),
\end{array}
$$

where 6.3 is the theoretical maximum ATP/O ${ }_{2}$ (Kushmerick 1983; Scheffler 2007).

\section{Cardiolipin and phosphatidylglycerol}

Cardiolipin is an essential phospholipid component of the mitochondrial inner membrane. Markers of cardiolipin metabolism were determined in the right-sided myocardium by high-performance liquid chromatography-mass spectrometry (Houtkooper et al. 2009). The ratio of the most abundant phosphatidylglycerol [PG(34:1), a precursor of cardiolipin] and cardiolipin [CL(72.8), containing four linoleic acid fatty acid side-chains] was used as indicator of cardiolipin metabolism. This ratio (PG/CL) is expressed relative to the mean ratio in controls (mean $\mathrm{PG} / \mathrm{CL}$ is set to 1 ).

\section{Statistics}

Statistical analyses were performed using GraphPad Prism 7.0 (GraphPad Software, La Jolla, CA, USA). Linear regression lines were fitted through the data and slopes and intercepts were compared using ANOVA. 95\% confidence intervals $(95 \% \mathrm{CI})$ were calculated for the slopes and $y$-intercept. Values are mean \pm SD if not indicated otherwise.

\section{Results and discussion}

Pilot experiments indicated that the original fixation time (10 min) was critical in heart muscle. 2-min fixation was sufficient to prevent precipitate covering the section, while maintaining maximal ATPase activity. We did not observe a precipitate covering the section after $2 \mathrm{~min}$ of fixation nor the formation of precipitate in the incubation medium, indicating that all phosphate produced in the section precipitated close to the site of formation.

\section{Absorbance increases linearly with incubation time and section thickness}

Figure $1 \mathrm{a}, \mathrm{b}$ shows the increase in absorbance over time and the images used to measure the absorbance. In all conditions except incubation without ATP, the increase in absorbance was linear with incubation time and significantly different from zero $(p<0.0001$ for test, DNP, oligomycin and oligomycin + preincubation, $p=0.17$ for no ATP). However, we observed a $y$-intercept for all conditions $\left(A_{550}=0.094 \pm 0.005\right.$ on average). The regression lines of the oligomycin incubations with and without preincubation were similar, indicating that oligomycin binding to $\mathrm{F}_{1} \mathrm{~F}_{0}$ ATPase is fast, and that preincubation is not required. However, part of the ATPase activity is insensitive to oligomycin.

The increase in absorbance with increasing section thickness and the corresponding images are shown in Fig. 1c, d. In all conditions, the increase in absorbance was linear over the measured interval and significantly different from zero $(p<0.0001$ for all, including no ATP). A $y$-intercept was again present in all conditions $(0.099 \pm 0.010$ on average, 0.066 for no ATP alone). Note that blank absorbance is set just outside the section, indicating that the intercept absorbance in Fig. 1d is due to the interaction of light with the unstained section itself, e.g., due to diffuse light scattering at the cut surfaces of the section. Were it due to PbS absorbance, a proportional relationship was expected in incubations without ATP. The absorbance increase with section thickness of unstained sections is relatively small: 0.0032 absorbance units/ $\mu \mathrm{m}$ section thickness. Again, the relationships for oligomycin incubations with and without preincubation are similar, excluding diffusion effects on oligomycin binding. 
a

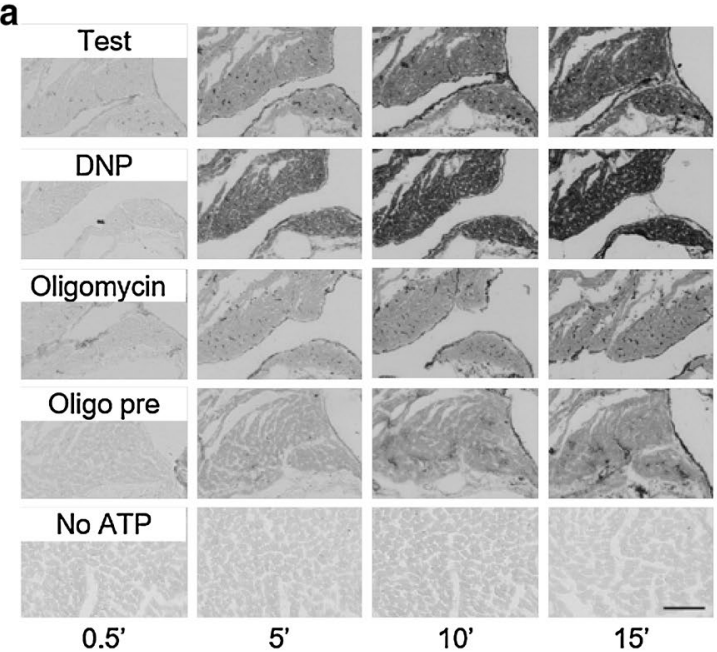

b

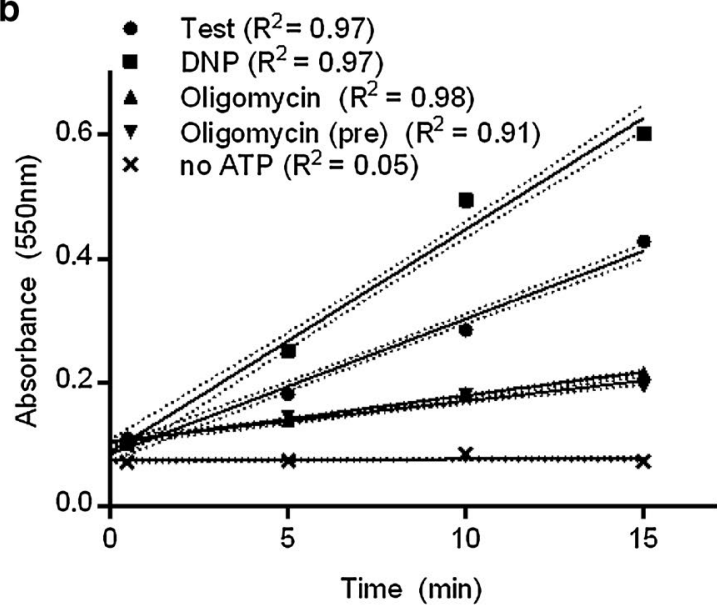

Fig. 1 Quantification of time- and sections thickness series. a Representative images of serial sections that were incubated for $0.5 \mathrm{~min}$, $5 \mathrm{~min}, 10 \mathrm{~min}$ or $15 \mathrm{~min}$. b The absorbance values of the sections shown in a were measured and plotted against incubation time. c Representative images of serial sections with different thickness, all incubated for $10 \mathrm{~min}$. d The absorbance values of the sections shown

\section{Specificity of the reaction}

A $\mathrm{PbS}$ precipitate is formed even in preparations incubated with oligomycin, indicating that the precipitate is not entirely due to mitochondrial $\mathrm{F}_{1} \mathrm{~F}_{\mathrm{o}}$ ATPase or that oligomycin does not completely inhibit $\mathrm{F}_{1} \mathrm{~F}_{\mathrm{o}}$ ATPase instantaneously. Since oligomycin is present in excess (20 times $\mathrm{IC}_{50}$, Nesci et al. 2014) and addition of DNP to oligomycin containing media did not increase the final absorbance after 10 min incubation (result not shown), it is likely that that oligomycin inhibition was complete. Also, both validations (for time and section thickness) showed no differences in the slope or intercept of incubations with oligomycin with or without preincubation. It is thus likely that the time needed for inhibition of
C

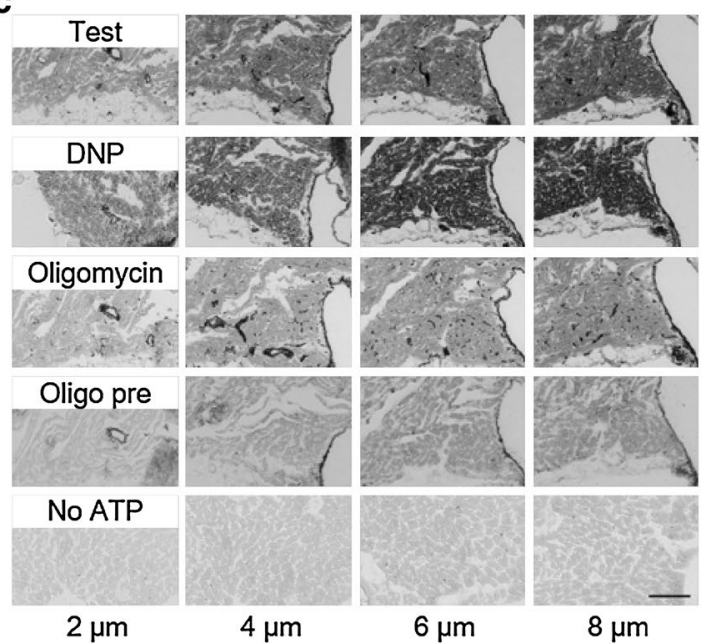

d

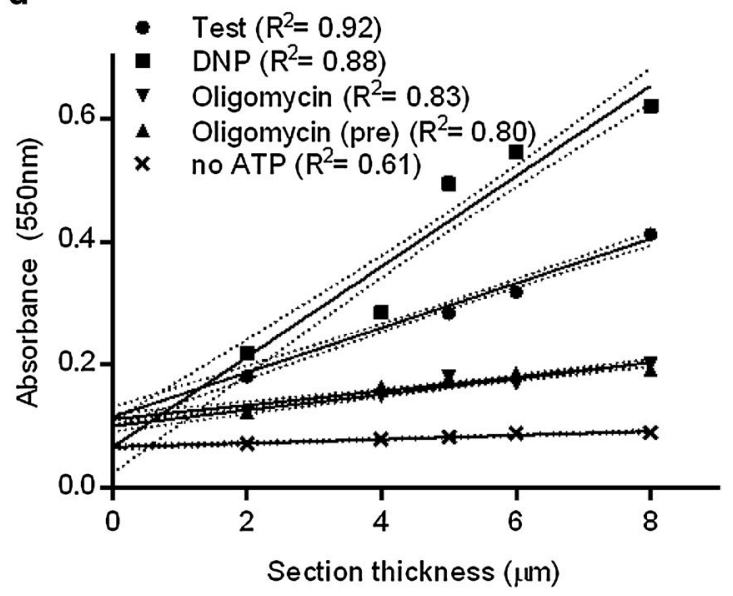

in $\mathbf{c}$ were measured and plotted against sections thickness. Data at $5 \mu \mathrm{m}$ in from $\mathbf{b}$, serial sections shown in $\mathbf{a}$ and $\mathbf{c}$ are both from the same heart. $R^{2}$ values are given in $\mathbf{b}$ and $\mathbf{d}$ for the linear regression lines of absorbance with time or sections thickness, respectively. Dotted lines around the regression lines represent $95 \%$ confidence intervals. Scale bars represent $100 \mu \mathrm{m}$. DNP 2,4-dinitrophenol

$\mathrm{F}_{1} \mathrm{~F}_{\mathrm{o}} \mathrm{ATPase}$ is negligible compared to the incubation time. Therefore, we conclude that oligomycin-insensitive ATPases in cardiomyocytes contribute to the absorbance, as discussed by Meijer and Vloedman (1980).

In addition, these could be myosin ATPase, T-tubular MgATPase (Hidalgo et al. 1983) or ecto-ATPase (Zinchuk et al. 2002). Quantification of these ATPases is beyond the scope of the present study. Ecto-ATPase is mainly located on the outside of the cardiomyocyte sarcolemma and endothelial cells, but has also been detected in T-tubules (Zinchuk et al. 2002). Myosin ATPase does contribute since treatment of sections with $10 \mu \mathrm{M}$ blebbistatin for $10 \mathrm{~min}$ after fixation reduced the absorbance after oligomycin incubation from $0.18 \pm 0.02$ to $0.14 \pm 0.01$ (after subtraction of intercept 


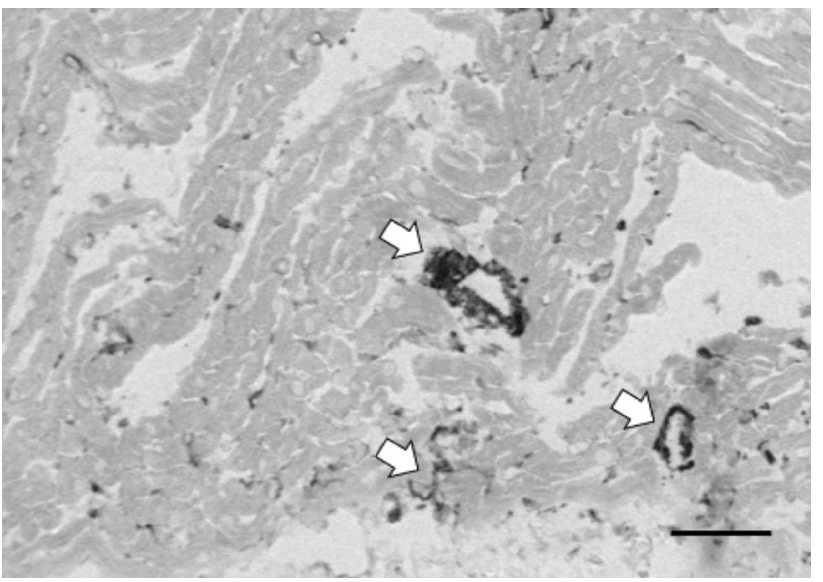

Fig. 2 Enlargement of the incubation with oligomycin for $10 \mathrm{~min}$, in a section of $5 \mu \mathrm{m}$, as shown in Fig. 1a. White arrows indicate cells with high ATPase activity in vessel walls. Also, larger spots with high ATPase activity are seen, possibly smaller vessels and capillaries. Scale bar represents $50 \mu \mathrm{m}$

absorbance: from $0.09 \pm 0.02$ to $0.05 \pm 0.01$ ), suggesting that about half of oligomycin-insensitive ATPase activity is myosin ATPase (result not shown). Triton X-100 partly deactivates T-tubular MgATPase (Ebus and Stienen 1996), but cannot be used as inhibitor in the present assay because it solubilizes mitochondrial membranes (Gurtubay et al. 1980). Also, high ATPase activity in vessel walls and endothelial cells is obvious, as shown in Fig. 2. Activity from sarcolemmal ecto-ATPases can easily be excluded from the absorbance measurements, by only measuring the absorbance in the center of the cells.

Thus, accurate determinations of the coupling state using Meijer and Vloedman's method require a correction for background ATPase activity by subtracting absorbance measured after incubation with oligomycin. Because the intercept is also present in the sections incubated in the presence of oligomycin, subtraction of the absorbance obtained after oligomycin incubation also provides this intercept correction.

Meijer and Vloedman (1980) demonstrated that addition of $\mathrm{Pb}^{2+}$ ions to the biochemical assay decreased $\mathrm{F}_{1} \mathrm{~F}_{\mathrm{o}} \mathrm{ATPase}$ activity. The inhibition decreased with the amount of tissue in the assay: from $88 \%$ inhibition at $2 \mathrm{mg}$ tissue $/ \mathrm{ml}$ to $23 \%$ inhibition at $50 \mathrm{mg}$ tissue $/ \mathrm{ml}$ homogenization medium, suggesting that inhibition is negligible beyond $200 \mathrm{mg}$ tissue/ml. We conclude that inhibition of the enzyme in the section by $\mathrm{Pb}^{2+}$ is negligible in the present study, because tissue density is $1050 \mathrm{mg} / \mathrm{ml}$ and because the free $\mathrm{Pb}^{2+}$ concentration near the enzyme must be lower than $3.6 \mathrm{mM}$ to maintain the constant flux of lead ions into the section and because $\mathrm{Pb}^{2+}$ will at least partly precipitate with phosphate before it reaches the enzyme. It

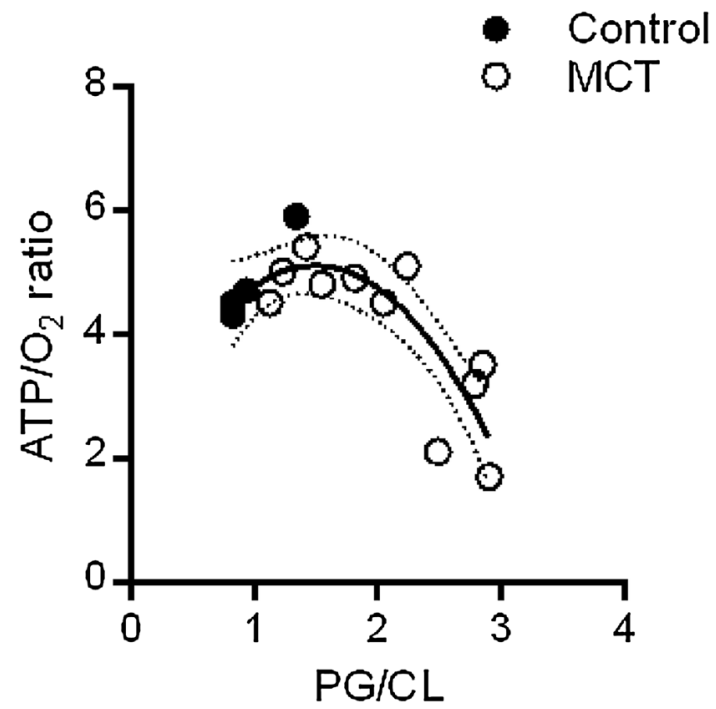

Fig. 3 ATP $/ \mathrm{O}_{2}$ ratios calculated from measured absorbance values, both in control and MCT-induced pulmonary hypertensive rats. A second-order polynomial was fitted through the data (best fit curve $\left.\mathrm{ATP} / \mathrm{O}_{2}=-1.4 \quad(\mathrm{PG} / \mathrm{CL})^{2}+4.18 \quad(\mathrm{PG} / \mathrm{CL})+1.99, \quad R^{2}=0.69\right) . \quad P G$ phosphatidylglycerol, $C L$ cardiolipin

can be calculated using Lambert-Beer's law that the rate of phosphate precipitation in the section corresponds to $0.34 \mathrm{mM} / \mathrm{s}$ in the presence of DNP (Fig. 1b).

\section{ATP $/ \mathrm{O}_{2}$ ratios in myocardial control and pulmonary hypertensive rats}

After correction, the absorbance data in test and positive controls obey Lambert-Beer's law and thus, it is possible to estimate the effect of proton permeability on ATP/ $\mathrm{O}_{2}$. The result is shown in Fig. 3 where the relationship between the ATP $/ \mathrm{O}_{2}$ ratio calculated from proton permeability is plotted against a marker of cardiolipin metabolism, the PG/CL ratio. Paired determinations in the right ventricular free walls of healthy and pulmonary hypertensive rats show a normal $\mathrm{ATP} / \mathrm{O}_{2}=5$ in healthy hearts but a non-linearly decreasing coupling ratio with increasing PG/ CL ratio. Low $\mathrm{ATP} / \mathrm{O}_{2}$ ratios of around two have severe energetic consequences. These results suggest that mitochondrial proton leak could be an important contributor to reduced myocardial efficiency in chronic heart failure. The mechanism behind the relationship in Fig. 3 requires further study. The present histochemical method can be applied to myocardial samples smaller than a milligram, allowing for diagnostic tests of mitochondrial function in myocardial biopsies.

Acknowledgements Eva L. Peters was funded through a VICI Grant (2002406) by the Dutch Organization for Scientific Research (NWO). 
Open Access This article is distributed under the terms of the Creative Commons Attribution 4.0 International License (http://creativeco mmons.org/licenses/by/4.0/), which permits unrestricted use, distribution, and reproduction in any medium, provided you give appropriate credit to the original author(s) and the source, provide a link to the Creative Commons license, and indicate if changes were made.

\section{References}

Barclay CJ, Widen C (2010) Efficiency of cross-bridges and mitochondria in mouse cardiac muscle. Adv Exp Med Biol 682:267-278. https://doi.org/10.1007/978-1-4419-6366-6_15

Blanco CE, Sieck GC (1992) Quantitative determination of calciumactivated myosin adenosine triphosphatase activity in rat skeletal muscle fibres. Histochem J 24:431-444. https://doi.org/10.1007/ BF01089105

Ebus JP, Stienen GJM (1996) Origin of concurrent ATPase activities in skinned cardiac trabeculae from rat. J Physiol 492:675-687. https ://doi.org/10.1113/jphysiol.1996.sp021337

Gurtubay JI, Goñi FM, Gómez-Fernández JC et al (1980) Triton X-100 solubilization of mitochondrial inner and outer membranes. J Bioenerg Biomembr 12:47-70. https://doi.org/10.1007/BF00745012

Heytler PG, Prichard WW (1962) A new class of uncoupling agentscarbonyl cyanide phenylhydrazones. Biochem Biophys Res Commun 7:272-275. https://doi.org/10.1016/0006-291X(62)90189-4

Hidalgo C, Gonzalez ME, Lagos R (1983) Characterization of the $\mathrm{Ca}^{2+}$ - or $\mathrm{Mg}^{2+}$-ATPase of transverse tubule membranes isolated from rabbit skeletal muscle. J Biol Chem 258:13937-13945

Hoch FL (1998) Cardiolipins and mitochondrial proton-selective leakage. J Bioenerg Biomembr 30:511-532. https://doi. org/10.1023/A:1020576315771

Houtkooper RH, Rodenburg RJ, Thiels C et al (2009) Cardiolipin and monolysocardiolipin analysis in fibroblasts, lymphocytes, and tissues using high-performance liquid chromatography-mass spectrometry as a diagnostic test for Barth syndrome. Anal Biochem 387:230-237. https://doi.org/10.1016/j.ab.2009.01.032

Kushmerick JM (1983) Energetics of muscle contraction. In: Peachey LD (ed) Handbook of physiology, skeletal muscle. Lippincott Williams and Wilkins, pp 189-236

Laborde K, Bussieres L, De Smet A et al (1990) Quantification of renal Na-K-ATPase activity by image analysing system. Cytometry 11:859-868. https://doi.org/10.1002/cyto.990110802

Lee-de Groot MBE, Des Tombe AL, Van der Laarse WJ (1998) Calibrated histochemistry of myoglobin concentration in cardiomyocytes. J Histochem Cytochem 46:1077-1084. https:// doi.org/10.1177/002215549804600912

Lou F, Van der Laarse WJ, Curtin NA, Woledge RC (2000) Heat production and oxygen consumption during metabolic recovery of white muscle fibres from the dogfish Scyliorhinus canicula. J Exp Biol 203:1201-1210

Meijer AEFH, Vloedman AHT (1980) The histochemical characterization of the coupling state of skeletal muscle mitochondria. Histochemistry 69:217-232. https://doi.org/10.1007/BF00489769

Murphy E, Ardehali H, Balaban RS et al (2016) Mitochondrial function, biology, and role in disease: a scientific statement from the American Heart Association. Circ Res 118:1960-1991. https:// doi.org/10.1161/RES.0000000000000104

Nesci S, Ventrella V, Trombetti F et al (2014) Thiol oxidation is crucial in the desensitization of the mitochondrial $\mathrm{F}_{1} \mathrm{~F}_{\mathrm{o}}$-ATPase to oligomycin and other macrolide antibiotics. Biochim Biophys Acta Gen Subj 1840:1882-1891. https://doi.org/10.1016/j.bbage n.2014.01.008

Pham T, Nisbet L, Taberner A et al (2018) Pulmonary arterial hypertension reduces energy efficiency of right, but not left, rat ventricular trabeculae. J Physiol 596:1153-1166. https://doi.org/10.1113/ JP275578

Picard M, Taivassalo T, Gouspillou G, Hepple RT (2011) Mitochondria: isolation, structure and function. J Physiol 589:4413-4421. https://doi.org/10.1113/jphysiol.2011.212712

Scheffler IE (2007) Mitochondria, 2nd edn. Wiley, Hoboken

Van Noorden CJF, Jonges GN (1992) Molecular extinction coefficients of lead sulfide and polymerized diaminobenzidine as final reaction products of histochemical phosphatase reactions. Cytometry 13:644-648. https://doi.org/10.1002/cyto.990130613

Van Eif VWW, Bogaards SJP, Van der Laarse WJ (2014) Intrinsic cardiac adrenergic (ICA) cell density and MAO-A activity in failing rat hearts. J Muscle Res Cell Motil 35:47-53. https://doi. org/10.1007/s10974-013-9373-6

Wong YY, Handoko ML, Mouchaers KTB et al (2010) Reduced mechanical efficiency of rat papillary muscle related to degree of hypertrophy of cardiomyocytes. Am J Physiol Heart Circ Physiol 298:H1190-H1197. https://doi.org/10.1152/ajpheart.00773.2009

Wong YY, Ruiter G, Lubberink M et al (2011) Right ventricular failure in idiopathic pulmonary arterial hypertension is associated with inefficient myocardial oxygen utilization. Circ Hear Fail 4:700 706. https://doi.org/10.1161/CIRCHEARTFAILURE.111.962381

Zinchuk VS, Okada T, Seguchi H (2002) Combined biochemistry and histocytochemistry as a tool to investigate ecto-ATPase in the cardiac muscle. Microsc Res Tech 58:427-431. https://doi. org/10.1002/jemt.10157 